In the symposium as a whole the damping of rocks to earthquake waves $(<1 \mathrm{c} / \mathrm{s})$ and to seismic exploration waves $(10-150 \mathrm{c} / \mathrm{s})$ was not discussed, and little was said about frequencies of $5,000 \mathrm{Mc} / \mathrm{s}$ and upwards. Little omerged in discussion concerning equipment design and techniques, although no doubt useful interchanges of information occurred privately. Littlo common ground is shared between workers on metals and hard single crystals on one hand, dealing with loss angles down to $3 \times 10^{-8}$, and workers on polymers dealing with loss angles of $0 \cdot 1-1 \cdot 2$ radians. Even so, an occasional symposium, in which such widely diverse fields of interest are included, serves a useful purpose. G. Bradfield

' Nature, 167, 1021 (1951).

${ }^{2}$ Proc. Symp. (1962). J. Phys. Soc., Japan, 18, Suppl. 1, 2,3 (1963).

${ }^{3}$ Redwood, M., Mechanical Waveguides (Pergamon Press, 1960).

- Bodner, S. R., and Kolsky, H., Proc. 3rd U.S. Nat. Cong. App. Mech.

(Amer. Soc. Mech. Eng.), 495 (1958).

${ }^{5}$ Kolsky, H., Stress Waves in Solids, first ed. (Clarendon Press, 1953).
${ }^{6}$ Kono, R., J. Phys. Soc., Japan, 15, 718 (1960); 16, 1580, 1792 (1961).

7 Daniel, M. R., and Mackinnon, K., Phil. Mag., 8, 537 (1963).

Truell, R, and Elbaum, C., in Handbuch der Physik, 11/2, edit. by Flügge, S. (Springer-Verlag, 1961).

'Southgate, P. D., Proc. Phys. Soc., B, 70, 804 (1957).

${ }^{10}$ Hasiguti, R. R., Igata, N., and Ueki, M., Acta Met., 12, 947 (1964).

${ }^{11}$ Snowdon, J. C., Rubberlike Materials, Their Internal Damping and Role in Vibration Isolation (Ordnance Research Laboratory, The Pennsylvania Vibration Isolation (Ordnance Research Laboratory, The P
State Univ., University Park, Penn., U.S.A., June 1964).

${ }^{12}$ Astbury, N. F., and Davis, W. R., Trans. Brit. Ceramic Soc., 68, 1 (1964).

OTHER REFERENCES ON INTERNAL FRICTION INCLUDE:

Mason, W. P., Physical Acoustics and the Properties of Solids (New York: Van Nostrand Co., 1958).

Mason, W. P., in Handbuch der Physik, 11/1, edit. by Flüggc, S. (Berlin: Son, W. P., in Handbuch

Entwistle, K. M., in The Physical Examination of Metals, edit. by Chalmer, B., and Quarrell, A. G., second ed. (London: Arnold, 1961).

Weertmann, J., J. App. Phys., 26, 202 (1955).

Nowick, A. S., in Progress in Metal Physics, edit. by Chalmers, B, 4 (London: Pergamon Press, 1953).

Zenar, C., Elasticity and Anelasticity of Metals (Chicago University Press, 1948).

\title{
TENTATIVE CLASSIFICATION OF FOOD IRRADIATION PROCESSES WITH MICROBIOLOGICAL OBJECTIVES
}

$\mathrm{W}^{\mathrm{s}}$ E were recently asked, as members of an expert group, to define the main types of irradiation process applied to foods for microbiological reasons, and to suggest names for the types recognized. This article briefly records our joint conclusions.

With any kind of process for the preservation of food, two different broad microbiological objectives can be distinguished. In the first, the aim is to kill all microorganisms of significance in the food, and, where achieved by heating, the process is commonly called sterilization, though a few micro-organisms may remain alive but quiescent; this is the condition well known to food technologists as 'commercial sterility'. For this type of heating process, the French have a special name appertization, commemorating Nicolas Appert, who invented it. The second broad objective is to kill many, but by no means all, of the micro-organisms. When achieved by heating, this is called pasteurization; it may be done either to kill pathogenic organisms in particular, or to reduce the number of viable micro-organisms generally and so improve keeping quality.

The same broad division of objectives applies to irradiation, so that hitherto radiation processes have commonly been separated, from the microbiological point of view, into radiation sterilization and radiation pasteurization. However, we did not regard this classification as adequate, or these terms as very suitable.

Sterilization is at best an abstract concept, which cannot be verified experimentally over any sizable number of packages, and special difficulties arise with an irradiation process. While viruses are comparatively easily killed by heat, such killing cannot be guaranteed with any process of irradiation alone, under conditions practicable with foods. Consequently sterilization, in the commonly understood sense of producing almost complete absence of viable micro-organisms, cannot be reliably achieved with radiation at present.

Pasteurization, again, is normally understood to kill most viruses, but this certainly cannot be achieved with the relevant doses of radiation. Moreover, as was pointed out at the European Meeting on the Microbiology of Irradiated Foods (F.A.O./I.A.M.S., Paris 1960 (ref. 1)), in the case of radiation treatment the term pasteurization is undesirably ambiguous, being used to describe processes with two distinct aims, one aim concerned with public health and the other not, which in some countries would require different legislative treatments. Even with heat processing, a different term is needed: for example, milk for cheese-making is sometimes heated to diminish its population of micro-organisms, but the heat treatment is less severe than that defined as pasteurization; the need for a term to describe this procedure has been plain for ten years, and was recognized by the International Dairy Federation, which provisionally proposed the word thermization.

We therefore suggest the following working definitions for the main types of irradiation treatment intended to kill micro-organisms in foods :

Sterilization by irradiation would be the application to foods of doses of ionizing radiation which produce sterility, that is, total absence of all viable micro-organisms as determined by any known method. This state cannot at present be guaranteed with any radiation process practicable with foods.

Among the attainable microbiological objectives, we recognized three types distinguished according to objective, and defined as follows:

Type $I$ is the application to foods of doses of ionizing radiation sufficient to reduce the number and/or activity of viable organisms to such an extent that very few, if any, are detectable in the treated food by any recognized method (viruses being excepted) while no spoilage or toxicity of microbial origin is detectable no matter how long or under what conditions the food is stored in the absence of recontamination.

Type $I I$ is the application to foods of doses of ionizing radiation sufficient to reduce the number of viable specific non-spore-forming pathogenic micro-organisms (other than viruses) so that none is detectable in the treated food by any standard method.

Type III is the application to foods of doses of ionizing radiation sufficient to enhance keeping quality by causing substantial reduction in the numbers of viable specific spoilage micro-organisms.

It will be evident that sterilization by irradiation and Type $I$ treatments have both been indiscriminately covered by the term radiation sterilization, while radiation pasteurization also has covered treatments of both Types $I I$ and $I I I$.

The following are the names we suggest for these types of treatment: Type I, radappertization; Type II, radicida. tion; Type III, radurization; and the reasons for these suggestions are given as follows.

The prefix rad- or radi-stands for the radiation used. (Lat. radiare, to shine). We could not think of any term which would indicate more precisely what kinds of 
radiation are intended. The prefix gamma is too restrictive, excluding types of radiation which might be used. The form radio-promotes confusion with Hertzian waves. Terms like cold pasteurization may lead to confusion with different means, other than heat, of attaining the same objectives.

The aim of radappertization is just the same as that of appertization, to produce the condition of commercial sterility. With the prefix rad-, there is an almost exact description of the Type $I$ process. Appertization has always been understood to imply a heat treatment, but the prefix rad-clearly discounts this. There is the inconvenience that English-speaking bacteriologists, not aware of the work of Nicolas Appert, are not yet accustomed to use the word appertization. We consider, nevertheless, that the aptness of the term radappertization far outweighs these objections.

The term radicidation derives from Lat. radiare, to shine, and occidere, to kill. The common use of the root -cide in words like germicido and bactericide has given it a more general connotation than would be desirable here, where the implication is towards some particular species. Hence, the specificity of aim implied in Type $I I$ treatments is not apparent in the term radicidation; and the best solution seems to be the usage, for example Salmonella radicidation, as one might say Salmonella disinfection. Further, radicidation bears misleading resemblance to radical, radish, etc., derived from Lat. radix, root. An alternative variation, radioccidation, is rejected because of written resemblance to radio and spoken resemblance to oxidation, besides possible confusion with Occident. Another alternative, irracidation, derived from irradiation and the root-cide, does not evidently contain the root rad-; and has the further inconvenience of seeming to entail an unnecessary prefix of ir- to the corresponding terms radappertization and radurization.

Radurization, based on rad-plus Lat. durare, to last or endure, expresses well the aim of the Type III process, to make the food more stable by means of radiation. The obvious defect of this term is that it does not indicate any connexion with microbiology. Further, it seems to verge on barbarism when rendered into French.
We submit that the foregoing classification of types of radiation treatment is logical; and adequate, for the present, because it seems premature to try to deal now with conceivable but as yet ill-defined combinations of radiation with, for example, heat or chemical preservatives.

As regards the terms we have suggested to designate the main types of treatment, however, we do not claim that they are anything more than the best we can suggest. We shall be interested to hear further suggestions.

Atomic Energy Branch,

H. E. Goreslint

Food and Agriculture Organization of the United Nations,

Rome.

M. INGRAM

Director, Meat Research Institute,

Low Temperature Research Station,

Downing Street, Cambridge.

Dircetor, Institute of Hygiene,

P. MACÚC:H Bratislava.

(ix. Mocquor

Director, Central Station for Dairy

Research and Technology of

Animal Products,

C.N.R.Z.,

Jouy-en-Josas (Seine et Oise).

D. A. A. Mossel

Head, Laboratory of Microbiology,

Central Institute for Nutrition and Food Research,

Utrecht.

Director of Scientific Research,

California Packing Corporation, San Francisco, California.

Head, Microbiology Section,

Food and Drug Directorate,

Department of National Health and Welfare, Ottawa.

'Intern. J. App. Rad. Isotopes, 14 (I). 26 (1963).

\title{
VARIABILITY OF THE STRONTIUM-90 AND CAESIUM-137 BURDEN OF NATIVE PLANTS AND ANIMALS
}

\author{
By L. L. EBERHARDT \\ Biology Laboratory, Hanford Laboratories, General Electric Company, Richland, Washington
}

$\mathrm{K}^{\mathrm{N}}$ NOWLEDGE of the inherent variability of radionuclide burdens of plants and animals is obviously of considerable importance in planning any kind of radio. logical survey of such populations, whether for research or health-protection purposes. A potentially important additional feature of such knowledge is the prospect of making some inferences about the manner in which radionuclides may be distributed over the landscape, which in turn may have a direct bearing on the course of such materials through a food web and, in extreme circumstances, on the radiation exposure of individual items of the biota.

The work recorded here is primarily concerned with matorials originating in world-wide fall-out, and is restricted to the biologically important, long-lived nuclides strontium-90 and cæsium-137 (half-life approximately 30 years). Two sources of data, the Nevada Test Site and National Reactor Test Site (Idaho), receive radionuclides of local origin, but no attempt will be made here to evaluate the relative importance of contributions of local and world-wide origin. Only data on native plants and animals have been used here, principally to avoid uncertainties about origin of domestic animal food supplies, and 'pooling' of samples from large areas.

Where possible, I have used only records obtained over relatively short-time intervals on areas of restricted size.

It is generally accapted that the bulk of world-wide fall-out is brought to the ground by precipitation, and it thus seems logical that variation in the local distribution of precipitation will contribute heavily to the variability of radionuclide deposition. The intensity of rainfall may influenco radionuclide deposition ${ }^{1}$, and presumably features of topography and wind direction and force will have important local offects on physical deposition.

Radionuclide burden of vegetation may be influenced by plant phenology, in regard to the season and duration of exposure relative to periods of maximum procipitation. and by surface characteristics of leaves and stems ${ }^{2}$. Very likely density of the stand of vegetation and the prospects for overlayering or stratification may also have a bearing 